\title{
Lipase-catalyzed Kinetic Resolution of Naproxen in Aqueous-organic Solvent Biphase System
}

\author{
Wei Zhang ${ }^{1, a}$, Zhenxing Wang ${ }^{1, b}$, Chunyu $\mathrm{Li}^{1, \mathrm{c}}$ and Jiaying $\mathrm{Xin}^{1, \mathrm{~d}^{*}}$ \\ ${ }^{1}$ Key Laboratory for Food Science and Engineering, Harbin University of Commerce, China

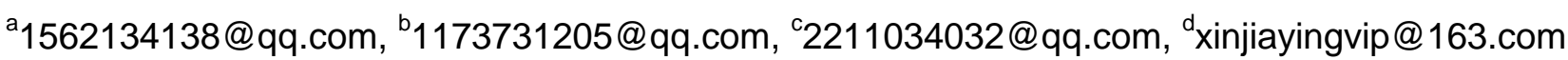

Keywords: Naproxen; Kinetic resolution; Aqueous-organic solvent biphase; lipase

\begin{abstract}
Dynamic kinetic resolution was used to overcome the problem that enantiomeric excess of product (eep) should been reduced with the increase of yield in the kinetic resolution, To obtain higher yield with higher enantiomeric excess of product (eep), and to overcome the disadvantage of kinetic resolution, the dynamic kinetic resolution system under microwave was established, Theoretically, dynamic kinetic resolution can achieve $100 \%$ of conversion. The establishment of dynamic kinetic resolution system is as follows: first of all, the silicone rubber hose (wall thickness $0.6 \mathrm{~mm}$, inner diameter of $7 \mathrm{~mm}$ ) was fully swelled, In the inner of the silicone rubber hose, the addition amount of $\mathrm{NaOH}$ was $2 \mathrm{~g}$, the addition amount of methanol and trimethylchlorosilane was $0.1 \mathrm{ml}$ and $0.2 \mathrm{ml}$, respectively. In the outer of the silicone rubber hose, the addition amount of isooctane was $50 \mathrm{ml}$, the addition amount of racemic naproxen methyl ester was $0.115 \mathrm{~g}$, the addition amount of Candida rrugose lpase was $0.285 \mathrm{~g}$, the addition amount of phosphate buffer solution $(0.2$ mol / L, pH 7.0) was1 ml.
\end{abstract}

\section{Introduction}

Theoretically, we can completely transform one enantiomer of substrate into the optically pure product, thus, the maximum output can reach 100\% [1]. However, the perfect match together of selective enzymatic hydrolysis and the chemical reaction in situ racemization is the biggest problem at this stage. In this paper silicone rubber tube has been used to separate the enzymatic racemic resolution process and the chemical separation process to avoid above problems [2]. On the basis of the base catalyzed in-situ chemical racemization and the Candida rugosa lipase catalyzed selective hydrolysis reaction, the S-Naproxen has been produced with higher enantiomer excess [3].

In recent years, some literature reported that some organic solvents is silicone swelling (such as silica gel immersed in n-hexane solution, the length can be increased by 20\%) [4], silica gel can be swollen by organic solvents and the organic solvents can penetrate the silicon film. Therefore, we chose silica gel as the material to separate the racemization reaction and the bio-selective resolution reaction. Because the larger lipase molecules can not penetrate the silicone rubber; and non-polar isooctane can swell and permeate the silicone rubber tube [5], so that naproxen methyl ester can be dissolved in isooctane, with the Isooctane and penetrated through the silica gel tube and contacted with the racemic catalyst for racemic reaction. For the phosphate buffer solution and $\mathrm{S}$ - naproxen products in isooctane, the solubility is particularly low and can not penetrate the silica gel tube and can not contact with the base catalysts. This avoids the racemization of product [6]. A small amount of trimethylchlorosilane has been added to the silica gel membrane because trimethylchlorosilane prevents hydrolysis and increases the rate of racemization of the substrate [7]. Strongly polar sodium hydroxide can not penetrate the silica gel tube and the enzyme and the product naproxen and buffer contact, will not make the enzyme inactivation [8]. Because of the selective permeation of the silica gel tube, the in-situ coupling between the biocatalysts reaction and the chemical racemization reaction is realized. 


\section{Materials and Methods}

Structure and Principle of the Reactor. The most important feature of this dynamic resolution reactor is to separate the chemically catalyzed in-situ racemization reaction and the biocatalytic resolution reaction as shown in the Figure 1. The silicone tube (wall thickness $0.6 \mathrm{~mm}$, inner diameter $7 \mathrm{~mm}$ ) was swollen in an organic solvent. In situ racemization reaction of naproxen methyl ester was catalyzed by the addition of sodium hydroxide, methanol and trimethylchlorosilane. And then putting a certain concentration of racemic naproxen methyl isooctane solution. By the addition of the CRL lipase, a certain concentration of racemic naproxen methyl isooctane solution, phosphate buffer solution and the rotor into silica gel tube. Finally, the three-necked flask was placed in a microwave reactor, the temperature sensor was inserted and the three-necked flask was closed. The rotation speed was adjusted to $200 \mathrm{rpm}$ to carry out the resolution reaction of naproxen methyl ester.

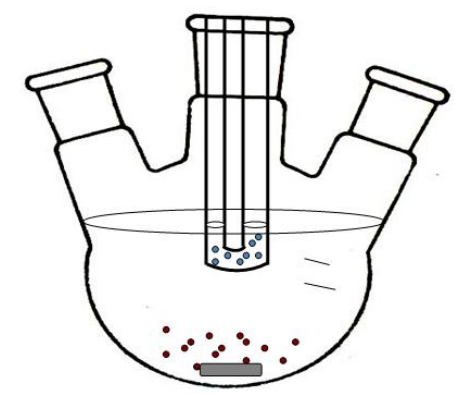

Figure 1. Schematic diagram of bioreactor configuration

Conversion Determination of Racemic Naproxen Methyl Ester. The silicone rubber hose (wall thickness $0.6 \mathrm{~mm}$, inner diameter of $7 \mathrm{~mm}$ ) was fully swelled in an organic solvent, In which were added 1,1.5,2,2.5,3 $\mathrm{g}$ of sodium hydroxide. $0.2 \mathrm{~mL}$ of methanol, $0.1 \mathrm{~mL}$ trimethylsilyl chloride, $0.115 \mathrm{~g} \mathrm{~S}$ re-dissolved in $50 \mathrm{~mL}$ iso-octane solution - naproxen methyl ester, $1 \mathrm{~mL}$ phosphate buffer solution $(0.2 \mathrm{~mol} / \mathrm{L}, \mathrm{pH} 7.0)$, together added to the reactor (without the addition of lipase), keep $45{ }^{\circ} \mathrm{C}$ for different time, extracting the substrate and product and enantiomeric excess of product were determinated by high performance liquid chromatography .

Determination of the Spontaneous Hydrolysis of Racemic Naproxen Methyl Ester. $0.115 \mathrm{~g}$ S-naproxen methyl ester was dissolved in $50 \mathrm{~mL}$ isooctane solution, and then $1 \mathrm{~mL}$ phosphate buffer solution $(0.2 \mathrm{~mol} / \mathrm{L}, \mathrm{pH} 7.0)$ was added to the membrane reactor without lipase to react, $\operatorname{keep} 45{ }^{\circ} \mathrm{C}$ for different time, Thin layer chromatography was used to detect the presence of naproxen in the silicone tube.

Determination of the Conversion of Naproxen Methyl Ester in the Resolution Reaction. $0.115 \mathrm{~g}$ racemic naproxen methyl ester was dissolved in $50 \mathrm{~mL}$ of isooctane and $1 \mathrm{~mL}$ phosphate buffer solution $(0.2 \mathrm{~mol} / \mathrm{L}, \mathrm{pH} 7.0)$ was added to each of 100, 125, 150, 175, $200 \mathrm{mg}$ of CRL fat Enzymes are added to the reactor together, keep $45{ }^{\circ} \mathrm{C}$ for different time, the enantiomer excess of racemic naproxen methyl ester and product $\mathrm{S}$-naproxen was determinate by high performance liquid chromatography.

Determination of the permeability of silicone tubes. The swollen silica gel tube was put into the reactor, and the isooctane without adding naproxen methyl ester was added into the silica gel tube. 50 $\mathrm{mL}$ isooctane solution was dissolved in $0.115 \mathrm{~g} \mathrm{~S}$-naproxen methyl ester, keep $45^{\circ} \mathrm{C}$ for different time, the silicone tube inside and outside the isooctane $0.1 \mathrm{~mL}$, diluted 50 times. Ultraviolet spectrophotometer has been used to measure the permeability of silicone tubes for S-naproxen methyl ester. . 


\section{Results}

Study on Dynamic Kinetics Resolution by Lipase-Catalyzed Microwave Method. In dynamic kinetic resolution reaction. The rate at which the substrate undergoes racemic reaction and the rate of permeation through the silica gel tube should be at least equal to the rate at which the resolution reaction catalyzed by lipase in order to ensure the effective implementation of the entire process. If the rate of racemization reaction and the rate of permeation are too slow, the slow reaction isomer would gradually surplus. Eventually this would result a decrease in the optical purity of the product.

$$
v=\frac{C \times c}{t}
$$

Among:

C-Reaction Conversion

$\mathrm{c}$-Substrate concentration $(\mathrm{mol} / \mathrm{L})$

$\mathrm{t}$-Reaction time $(\mathrm{h})$

$\mathrm{v}-$ Reaction rate $\left(\mathrm{mol} \cdot \mathrm{h}^{-1} \cdot \mathrm{L}^{-1}\right)$

According to the formula (1), if the substrate concentration and the reaction time of the racemization reaction and the resolution reaction are the same, the reaction rate can be expressed by the reaction conversion rate. That is, the kinetic resolution reaction can be carried out efficiently when the conversion of the racemization reaction and the resolution reaction is the same.

After $3 \mathrm{~h}$ reaction. according to the formula (2) and formula (3), the effect of the amount of sodium hydroxide on the conversion of racemization reaction was shown in Figure 1. The effect of the addition amount of CRL enzyme on the conversion was shown in Fig. 2
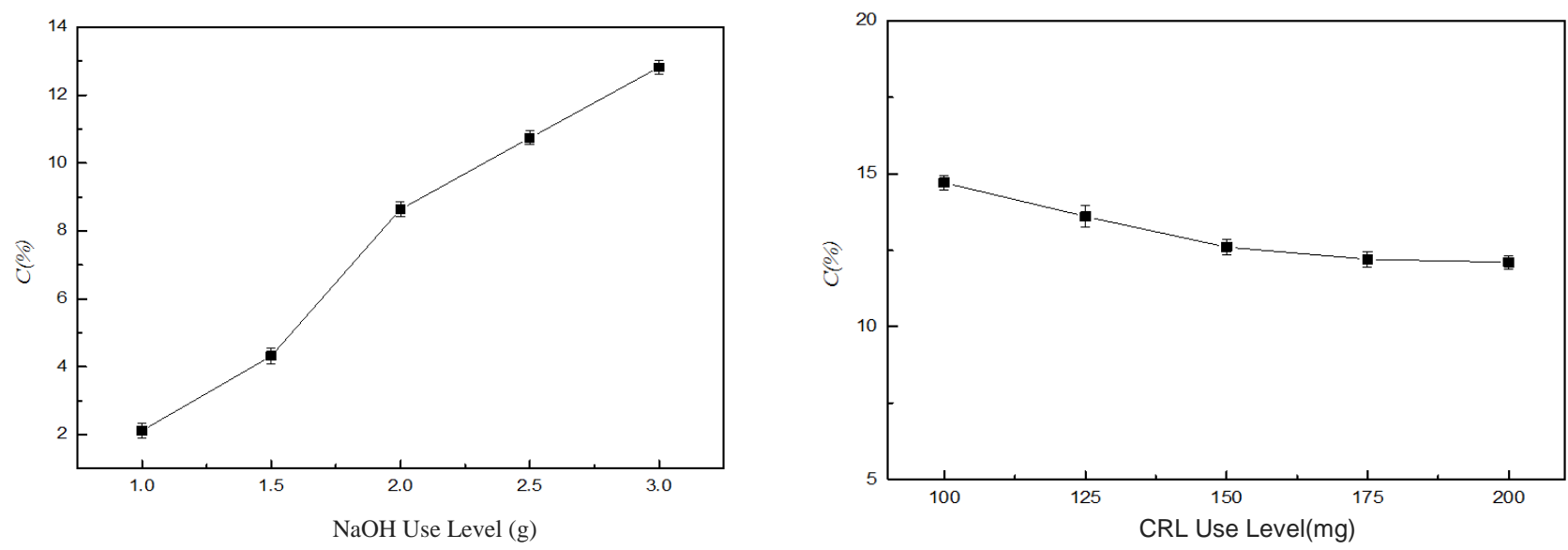

Figure 1. Effect of the amount of $\mathrm{NaOH}$ on racemic reaction conversion rate Effect of the amount of CRL on resolution reaction conversion rate

It can be seen from Figure 1 and Figure 2 that the racemization reaction conversion was $12.8 \%$ when the amount of sodium hydroxide added was $3 \mathrm{~g}$ with the same substrate concentration and reaction time for the racemization reaction and resolution reaction. When the addition amount of CRL enzyme was $150 \mathrm{mg}$, the conversion of the reaction was $12.6 \%$. The conversion of racemization reaction was slightly higher than that of the resolution reaction. That is, the rate of racemization reaction of the substrate was slightly larger than that of the resolution reaction, which can ensure the whole dynamic kinetic resolution process to be carried out effectively. So the amount of $0.115 \mathrm{~g}$ of the naproxen methyl ester was used, the amount of lipase added was $150 \mathrm{mg}$, and the amount of sodium hydroxide added was $3 \mathrm{~g}$.

$$
e e_{s}=\frac{[B]-[A]}{[B]+[A]}
$$




$$
\begin{gathered}
e e_{p}=\frac{[B]-[A]}{[B]+[A]} \\
C=\frac{e e_{s}}{e e_{s}+e e_{p}}
\end{gathered}
$$

Among:

Ees - the substrate enantiomer value

Eep - product enantiomeric value

[A]-S-naproxen or naproxen methyl peak area

[B]-R- naproxen or naproxen methyl peak area

\section{Summary}

The biggest advantage of dynamic resolution is that it can overcome the shortcomings of $50 \%$ of the maximum theoretical output value in the traditional splitting process. Not only can greatly improve the conversion rate but also to ensure that the product of high optical purity.

The dynamic resolution system of silicone tube $(0.6 \mathrm{~mm}, 7 \mathrm{~mm}$ in diameter, wall thickness) were swelling in organic solvents, in which $3 \mathrm{~g}$ sodium hydroxide, $0.2 \mathrm{~mL}$ methanol, $0.1 \mathrm{~mL}$ three methyl chlorosilane, silicone tube inside and outside adding dissolved isooctane $0.115 \mathrm{~g}$ racemic naproxen methyl ester $50 \mathrm{~mL}, 0.15 \mathrm{~g}$ CRL lipase, $1 \mathrm{~mL}$ phosphate buffer solution (0.2mol/L, $\mathrm{pH} 7.0)$.

\section{Acknowledgment}

The authors thank the Scientific Research Fund of Heilongjiang Province (GC13C111) for support.

\section{References}

[1] Han-Yuan Lin, Shau-Wei Tsai. Dynamic kinetic resolution of (R, S)-naproxen 2,2,2-trifluoroethyl ester via lipase-catalyzed hydrolysis in micro-aqueous isooctane $[\mathrm{J}]$. Journal of Molecular Catalysis B: Enzymatic. 2003, 24(25): 111-120.

[2] Elif Yilmaz, Mehmet Sezgin, Mustafa Yilmaz. Enantioselective hydrolysis of rasemic naproxen methyl ester with sol-gel encapsulated lipase in the presence of sporopollenin [J]. Journal of Molecular Catalysis B: Enzymatic, 2010, 62(2): 162-168.

[3] M.J. Hernáiz, J.M. Sánchez-Montero, J.V. Sinisterra. Hydrolysis of (R, S) 2-aryl propionic esters by pure lipase B from Candida cylindracea [J]. Journal of Molecular Catalysis A: Chemical. 1995, 96(3): 317-327.

[4] María J. Hernáiz, José M. Sanchez-Montero, José V. Sinisterra. Comparison of the enzymatic activity of commercial and semipurified lipase of Candida cylindracea in the hydrolysis of the esters of (R, S) 2-aryl propionic acids [J]. Tetrahedron. 1994, 50(36): 10749-10760.

[5] Giorno L, D'Amore E, Drioli E, et al. Influence of OR ester group length on the catalytic activity and enantioselectivity of free lipase and immobilized in membrane used for the kinetic resolution of naproxen esters [J]. Journal of Catalysis, 2007, 247(2): 194-200.

[6] Stecber,H.; Faber,K., Biocatalytic Dynamic Kinetic Resolution:Pd ${ }^{\circ}$ in Allylic Acetate Hydrolysis[J]. Synthesis., 1997, 1: 1

[7] Martin, V. S., Ikeda, M., Sharpless, K. B. Kinetic resolution of racemic allylic alcohols by enantioselective epoxidation. A route to substances of absolute enantiomeric purity [J]. $J . A m$. Chem Soc., 1981, 103, 6237-6240.

[8] Vedejs, E., Kendall, J. T., Aziridine Lithiation Using Lewis Acid Activation [J].J. Am. Chem. Soc.; 1997, 119: 6941-6942. 